\title{
Gsm Based Door Controller
}

\author{
B.Pradeepkumar Reddy, M.Reji
}

\begin{abstract}
Now a day's technology growth is incredibly quick. Day by day changes of technology is turning into user friendly So during this project we tend to planning to see concerning one a part of technology is "automatic shutter gap system interfacing with GSM module".
\end{abstract}

Keywords: GSM, automatic, door controller, microcontroller, embedded system.

\section{INTRODUCTION}

The title GSM based door controller is one of the good example for embedded system because all the operations in this project were controlled by an intelligent software at intervals system present inside the microcontroller. The main aim of this project is to regulate mainly to run motor forward or reverse in order to open or close the door by sending SMS using GSM. The appliances made of electrical or electronic components connected to the present system were accessed from any place within the world by using any sort of Mobile by the user. This manner it can able to work under the restricted vary of infrared and radio remote controls. this project enables us to remotely management door by causing plain text messages, like "*1" and "*2" all of which might be pre-programmed to the microcontroller and simply remembers later. It can able to manage up to eight external devices Short Message Service(SMS) is outlined as a text-based service. this allows us to a hundred and sixty characters to be sent from one transportable to a different. Unlike voice calls, SMS messages travel over various mobile networks with low-speed management channel. At the back side of the board the ULN2003 IC is used as relay driver, the sim holder is connected next to the IC where we can insert a valid sim. A 0-12 1amp transformer is needed to power up the module hence it acts as a power source. The Mobile operated door dominant has been designed in such some way that it will fulfills all the requirements of business and conjointly for private security. it's unnumbered application and may be utilized in completely different application for example, at one place it is employed by door dominant, whereas at another instance it is used for safety purpose. Here, we tend to area unit showing you the tactic of mistreatment the mobile to regulate our door open and close. It simply depends on the network of mobile and within the gift state of affairs, the mobile network is everyplace.
Revised Manuscript Received on August 14, 2019.

B.Pradeepkumar Reddy, ECE DEPT- Student

Saveetha school of engineering, SIMATS, Chennai, T.N, India.(Email: banapradeep29@gmail.com)

Dr.M.Reji, ECE DEPT- Associate Professor, Saveetha School Of Engineering, SIMATS, Chennai, T.N, India.(Email: reji@ saveetha.com )

\section{BLOCK DIAGRAM}

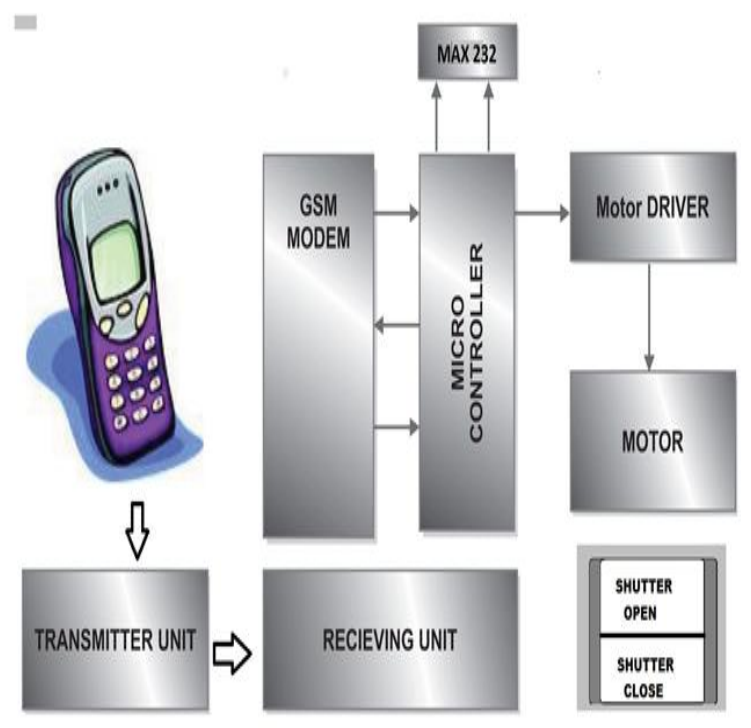

Fig.1 block diagram

In this project, the door controlled by a movable that creates a SMS (short message service) to the SIM (subscriber establish module) connected to the GSM electronic equipment. within the course of a SMS. The Decoder decodes the SMS into its equivalent digit and this binary vary is distributed to the pic16f877. The pic $16 f 877$ is preprogrammed to want call |a choice| a call $\}$ for any given input and outputs it's call to motor drivers thus on drive the motors for forward or backward motion. The mobile that makes a SMS to the SIM stacked inside the GSM equipment acts as an overseas. so this easy project does not would like the event of receiver and transmitter units. associate "c" program has been already drop into the PIC16F877.As per the program the IC generates the o/p knowledge. The output knowledge is served to a DC motors via ULN2003 that drives the motor consistent with the user necessities. 


\section{CIRCUIT DIAGRAM}

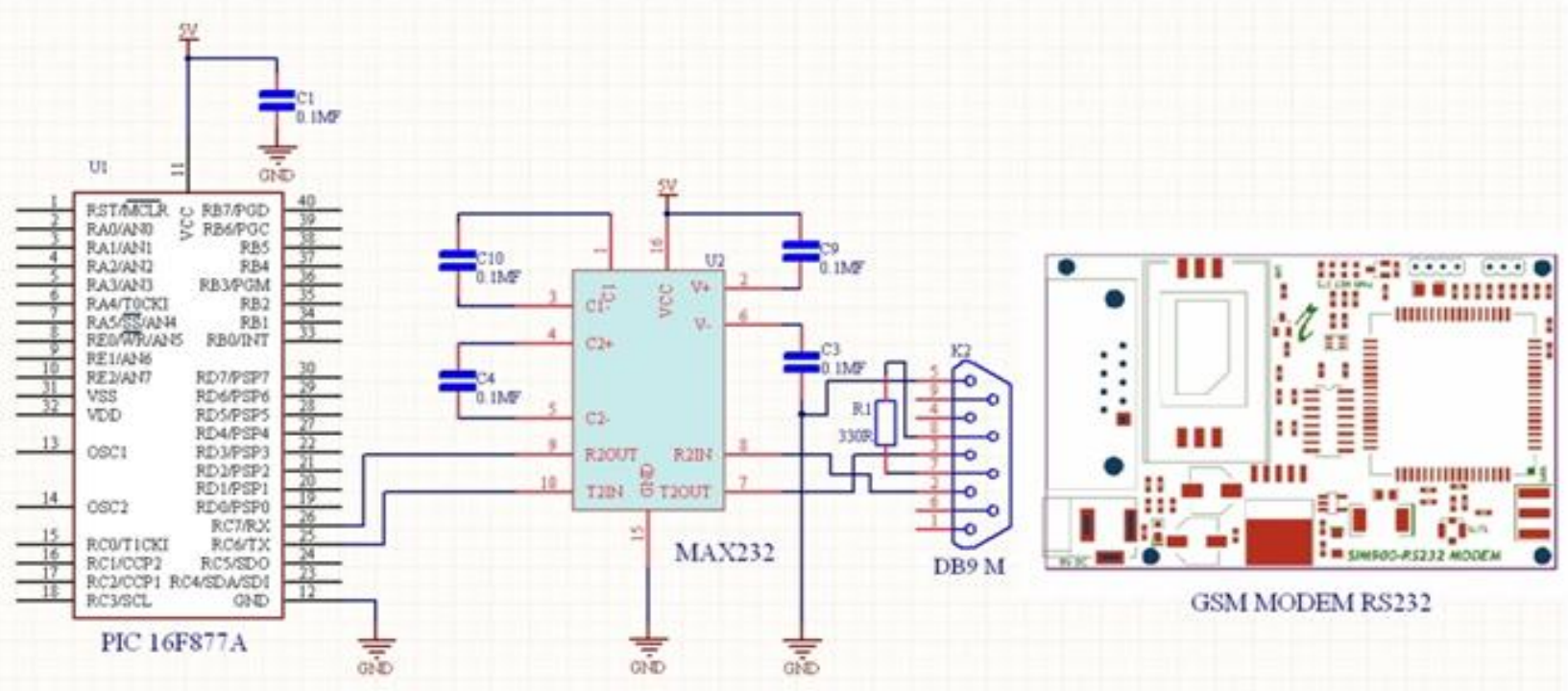

FIG.2 Circuit Diagram

We have used a GSM modem with RS232. RX pin of RS 232 is connected to TX pin of MAX 232 and RX pin of MAX 232 is connected to TX pin of RS232. This RX and TX pins of MAX232 is connected to RX, TX pins of pic16f877a.

\section{SOFTWARE SIMULATION}

A distinct event simulation may be a laptop model that mimics the operation of a true or projected system, like the every day operation of a bank, the running of associate degree line in an exceedingly manufactory, or the workers assignment of a hospital or decision canter.

Computer package or just package is any set of machinereadable directions that directs a computer's processor to perform specific operations. laptop package contrasts with element, that is that the physical element of computers.

\section{$M P L A B$}

MPLAB X IDE is a software developed by microchip that runs on a system in order to develop applications on silicon chip controllers. It can run on WINDOWS, LINUX and MAC operating systems. It is referred to as AN Integrated Development setting (IDE), as a result of it provides one integrated "environment" to develop code for the embedded small controllers.

MPLAB X IDE settings bought many changes to the PIC microcontroller development tool chain
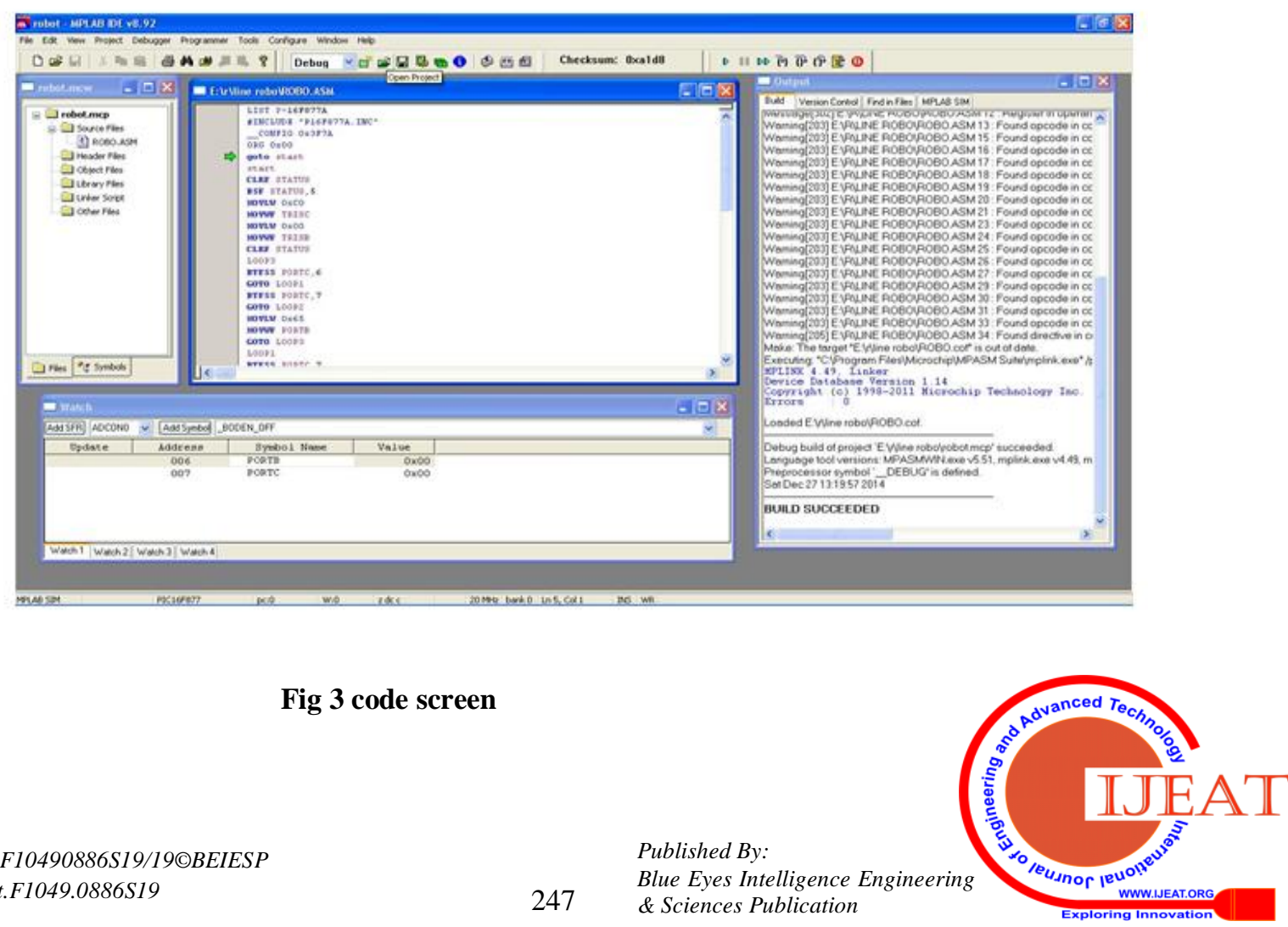
This picture demonstrates the working of project program in MP LAB simulation software with the addition of source file, with the combination of both BUILD and logic analysis.

\section{PROTEUS SIMULATION \& RESULTS}

The Advanced Simulation possibility may be value-added to all or any Proteus PCB style and Proteus VSM merchandise as well as the Starter Kit. It extend the practicality of the fundamental machine to produce a full varyof graph-based analyses. Graph based mostly simulation is resembling typical SPICEsimulation wherever you initially draw the circuit, set-up supply generators, choose points to be monitored then runthe machine. once the simulation is complete the results area unit displayed and you analysis these at your leisure. The Proteus style Suite with the Advanced Simulation options module makes this as easy afattainable.

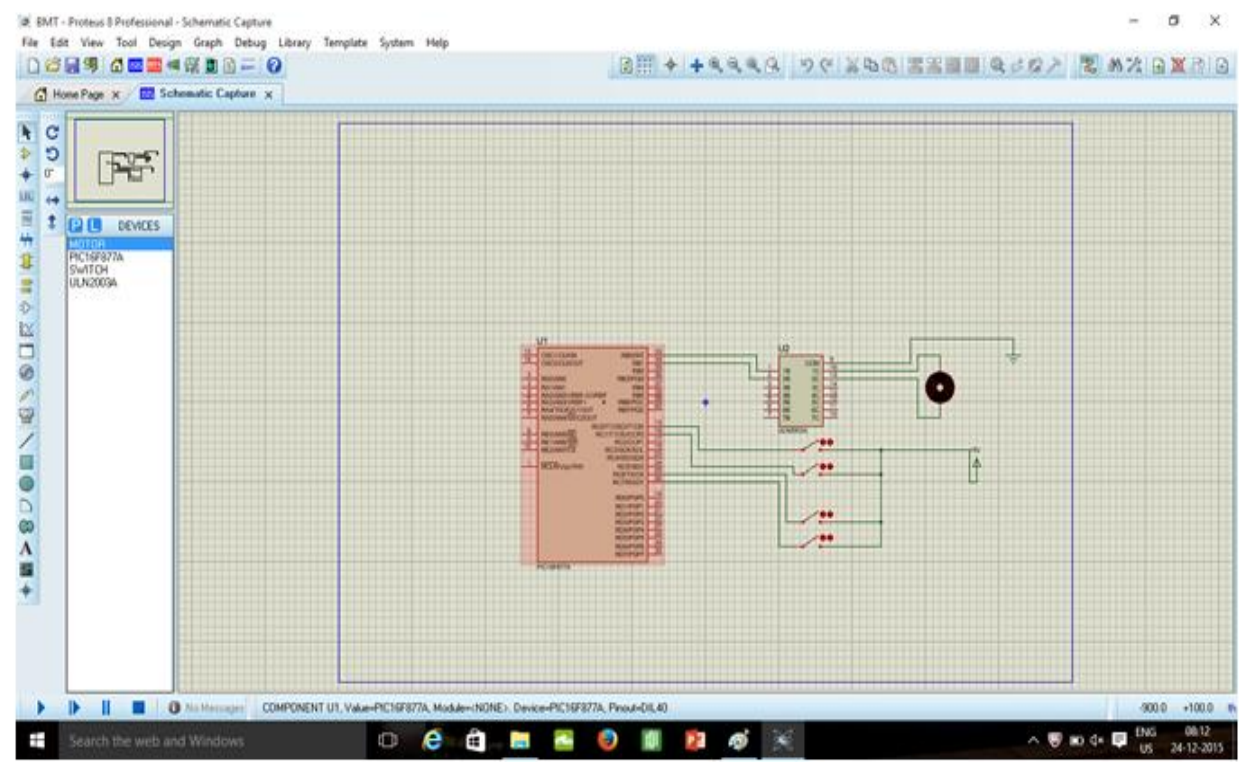

Fig 4

\section{Dc Motor}

A dc motor is the one which can able to work under ac or dc power source. It will convert the electrical energy into mechanical energy by using a magnet.

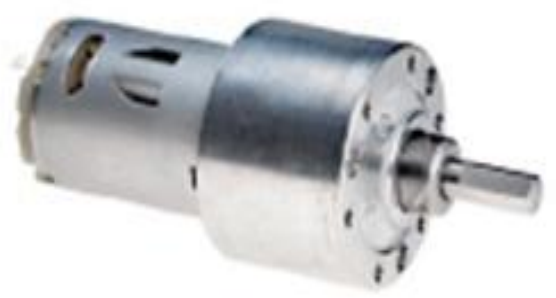

Fig.5 de motor

\section{Rack And Pinion}

Rack and pinion mechanism system consist of two components. A straight gear called the rack and round gear called the pinion. The rack can be considered as a very small segment of a infinite radius gear. When the pinion is revolving a rotation motion of the pinion gear. It is converted into the linear motion of the rack. On the other hand, the rack is pushed in one way the linear motion of rack is converted to a rotation of the pinion gear. The rack and pinion system works with the crank slider mechanism.
The system contains an extra top rack in addition to the bottom rack. The bottom rack is fixed to a plain and crank slider mechanism pushes the pinion gear to the back and forth. This push causes the pinion gear to rotate back and forth. Rotation motion of the pinion causes the top rack to move back and forth. However, you might miss one critical fact. If the radius of the crank is ' $R$ '. the stroke line of the pinion gear is ' $2 \mathrm{R}$ '. however the stroke line of the top track is $4 \mathrm{R}$. another interesting application of rack and pinion is powering trains uphill and downhill.

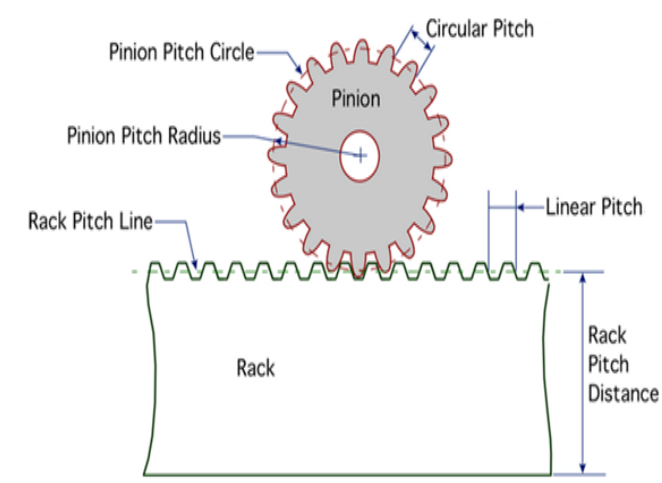

Fig 6

Published By:

Blue Eyes Intelligence Engineering \& Sciences Publication 


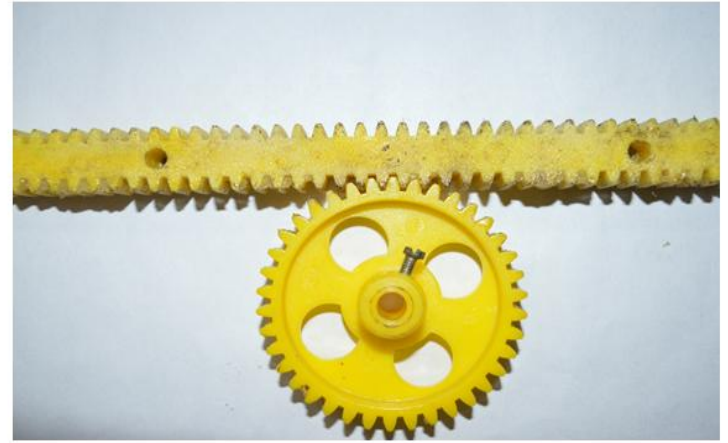

Fig 7

\section{SHUTTER OPENING AND CLOSING SYSTEM}

In this shutter opening system we opening the shutter by SMS code. we done rack \& pinion mechanism for opening and closing.

In the rack \& pinion mechanism works under the operation of motor. The motor shaft is connected in center of the cam. The motor is interfaced with driver from the dc motor driver is connected with controller when we send the SMS from mobile as that signal will transmits to receiver of GSM modem

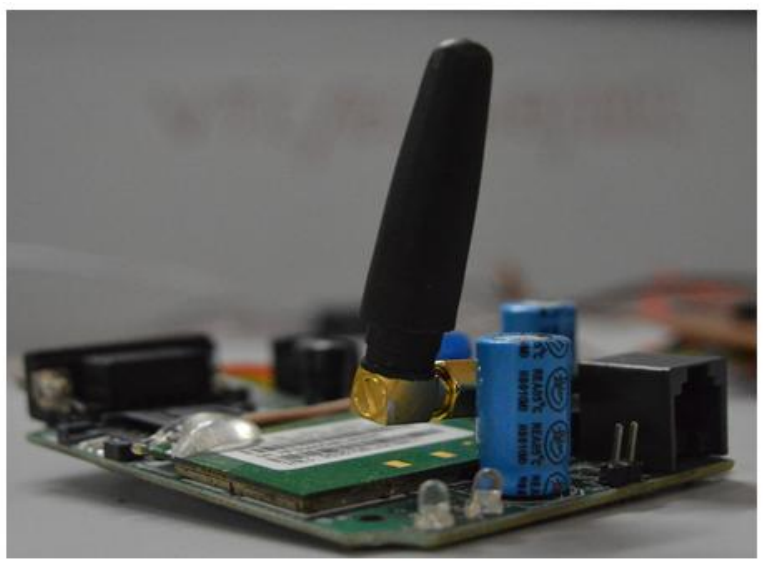

Fig 8(GSM)

That modem receives a signal and operate the motor in forward and reverse

When we SMS as $(* 1)$ motor will rotate forward and open the shutter till touch limit switch and it stop.

When we SMS as $(* 2)$ motor will rotate revers and close the shutter till touch limit switch and it stop.

\section{Final design:}
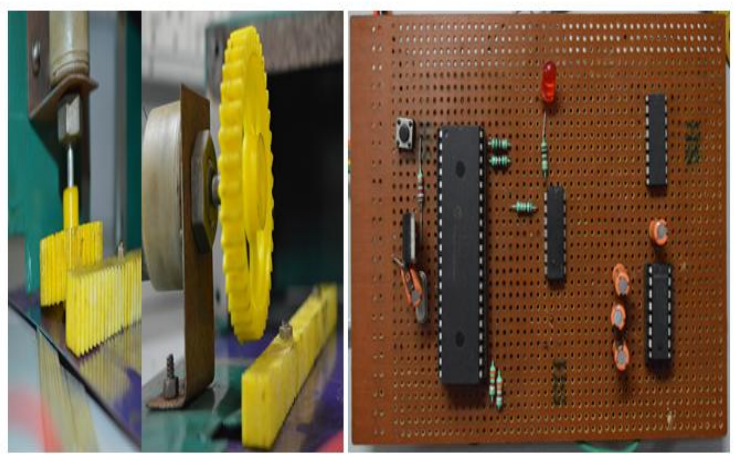

Fig 9

\section{WORKING}

First the SMS is received from the authorized person from the gsm modem the received information was transferred to microcontroller kit via max 232 as per the at command given by the controller to the modem control signal from SMS is extracted and used to control the device connected to it. For decoding the SMS we have to convert the septets of phone to octates program is loaded into microcontroller devices and circuit is connected to modem now the controller

\section{CONCLUSION}

Hence we tend to designed the user friendly technology for the sensible door open and shut system mistreatment the GSM module. The sensible SMS primarily based system for the door is helpful within the gift running world. Wherever ever will be by mistreatment only 1 press choice through your sensible device we will simply access our door system through our project. These is that the best and easy technology we tend to designed and enforced.

\section{REFERENCES}

1. C. K. Das, M. Sanaullah, H. M. G. Sarower, and M. M. Hassan, (2009). Development of a Cell Phone based Remote Control System: an Effective Switching System for Controlling Home and Office Appliances. International Journal of Electrical \& Computer Sciences, 9(10), pp. 23-29.

2. L. Pu, "An Improved Short Message Security Protocol for Home Network," in Proc. 2009 International Conference on Future Computer and Communication (FCC '09), Wuhan, pp. 62-65.

3. C. Peijiang and J. Xuehua, "Design and Implementation of Remote Monitoring System Based on GSM," in Proc 2008 Pacific-Asia Workshop on Computational Intelligence and Industrial Application (PACIIA '08), Wuhan, pp. 678-681.

4. L. Wei, Y. Min, C. Liang Liang, and C. Ping, "The Design of Intelligent Household Control System Based on Internet and GSM," in Proc. 2011 Second International Conference on Networking and Distributed Computing (ICNDC), Beijing, pp. 254-256.

5. B. I. Ahmad, F. Yakubu, M. A. Bagiwa, and U. I. Abdullahi. (2011). Remote Home Management: An alternative for working at home while away. World of Computer Science and Information Technology Journal (WCSIT), 1(4), pp. 144-147 